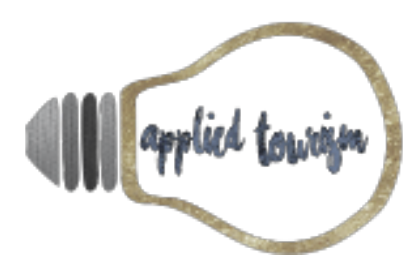

Volume 4, número 1, 2019, p. 41- 56

\title{
A IMAGEM DA FESTA NACIONAL DO DOCE - FENADOCE EM PELOTAS (RS), BRASIL, PERANTE A PERCEPÇÃO DOS RESIDENTES
}

\author{
Cristiane Berselli \\ Mestranda em turismo e hotelaria - Univali \\ bolsista capes \\ cristiane.berselli@gmail.com
}

Fabrícia Durieux Zucco

Doutora em Administração- UNINOVE Professora na Universidade do Vale do Itajaí - UNIVALI e Universidade Regional de Blumenau - FURB fabriciazucco@hotmail.com

Recebido: 06 de setembro, 2018 Aprovado: 27 de novembro, 2018

\section{RESUMO}

Eventos especiais como festivais são atividades que revitalizam as tradições locais, aumentam a qualidade de vida e a imagem da comunidade (Gursoy, Kim \& Uysal, 2004). Destaca-se que a imagem é uma dimensão importante a ser analisada na percepção dos residentes diante de um festival. Este estudo é exploratório, descritivo e quantitativo e teve por objetivo analisar a percepção dos residentes sobre a imagem da Fenadoce, antes da realização do evento. Os resultados descritivos através de média aritmética são apresentados $(n=111)$. Os resultados descritivos são apresentados através da média aritmética. Como principal resultado, a percepção dos residentes, de maneira geral, foi positiva perante a imagem da Fenadoce. Receberam pontuações positivas os elementos relacionados a benefícios a comunidade, custos percebidos, qualidade de serviços e infraestrutura. Somente o estacionamento é fator crítico que merece atenção dos gestores. Identificou-se que os residentes frequentam o evento em família e casais. As conclusões apresentam, também, apontamentos acadêmicos e gerenciais sobre estes resultados.

Palavras-chaves: Imagem, marca, festival. 


\section{INTRODUÇÃO}

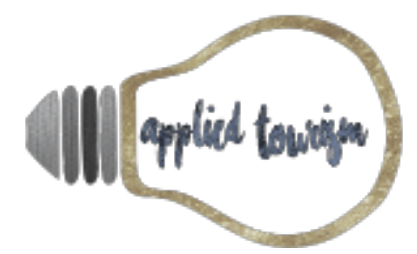

Volume 4, número 1, 2019, p. 41- 56

O turismo de eventos é considerado um dos segmentos mais promissores da atividade turística no que diz respeito a retorno financeiro (Getz, 2008). Os eventos fomentam a atratividade turística de um destino, devido a crescente importância na promoção de lugares dada a acirrada competitividade do turismo (Getz \& Page, 2016). No entanto, além de benefícios econômicos, do ponto de vista de Laing e Frost (2013) eventos culturais do tipo festivais podem ser catalisadores para melhorar ou regenerar comunidades, facilitar a compreensão e valorização da cultura e patrimônio local, também aumentar o apego dos autóctones ao lugar.

Apesar do estudo de Pimentel, Pinho e Vieira (2006) ter como foco a marca de destinos turísticos, as pesquisas sobre eventos turísticos e festivais também devem transmitir uma imagem de marca congruente com a identidade local. No entanto, como Wheeler, Frost e Weiler, (2011) salientam, a marca de destino é muitas vezes determinada pelas qualidades e valores percebidos pelo turista em oposição aos valores da comunidade, o que pode acarretar em percepções negativas dos residentes à atividade turistica. O mesmo pode ocorrer nos eventos e festivais.

Deng, Li e Shen (2013) salientam que mais estudos sobre a imagem de eventos necessitam serem realizados. A imagem de evento é um constructo multidimensional semelhante à imagem de destino que pode abranger vários componentes (Lai, 2018). Entre estes componentes estão os beneficios e custos pecebidos, para tanto, a gestão do evento deve desempenhar esforços em aspectos positivos como evidenciar a historia e a cultura, as atrações, as facilidades, infraestrutura, entre outros; para uma percepção positiva dos turistas e residentes.

Para os autores Machado, Medeiros e Luce (2011) a área de investigação do destination branding passa por uma miopia do marketing de destinos ao negligenciar algumas questões importantes como: não considerar a oferta dos concorrentes; negligenciar os residentes ao concentrar a antenção aos turistas; e desconsiderar questões sociais mais amplas. Quanto ao segundo ponto destacado, os autores chamam a antenção para que a percepção dos residentes serem seja colocada em evidência durante o processo de elaboração pelo branding ao construir a imagem do destino turístico, pois são estes atores que dão significado sobre seu próprio espaço. Da mesma forma, é importante compreender a imagem projetada na pela percepção dos residentes perante eventos e festivais.

Partindo dessas premissas teóricas, este estudo tem por objetivo analisar a percepção do residente de Pelotas/RS sobre a imagem da Festa Nacional do Doce - Fenadoce. Quanto aos procedimentos metodológicos, esta pesquisa é descritiva e exploratória, com abordagem aplicada de natureza quantitativa. Os procedimentos 


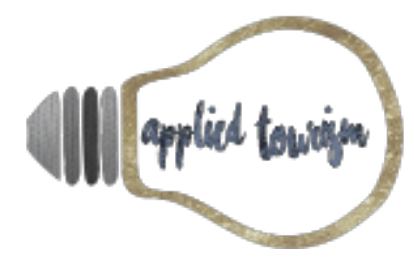

Volume 4, número 1, 2019, p. 41- 56

técnicos utilizados foram a pesquisa bibliográfica e survay. Foi utilizada uma amostra não probabilística de 125 respondentes com 111 questionários válidos. A organização do trabalho segue a seguinte ordem: Introdução, Referencial Teórico, Metodologia, Apresentação e análise de dados, e Considerações Finais.

\section{FUNDAMENTAÇÃO TEÓRICA}

\section{Eventos turísticos: festivais}

Destinos atraentes são aqueles que preservam sua cultura, identidade e patrimônio e são de enorme importância para aumentar a atratividade, desenvolver fluxo turístico e se inserir em um nicho de mercado (Stankova \& Vassenska, 2015). Os eventos podem contribuir na formação e reforço da imagem de um destino quando geridas numa estratégia integrada e coerente, definida por atributos diferenciadores (Guerreiro, Oom do Valle \& Mendes, 2011; Kotler \& Gertner, 2002).

Para Getz (2008) os eventos são fenômenos espaço temporais exclusivos pois é resultado da interação entre as pessoas e sistemas de gerenciamento. $\mathrm{O}$ autor afirma que o chamariz dos eventos é que eles nunca são iguais, e o visitante necessita estar no evento para desfrutar desta experiência. Eventos e festivais tem se tornado cada vez mais importantes no setor do turismo (Gertz, Andersson \& Carlsen, 2010). São importantes para o desenvolvimento regional, pois oportunizam desenvolvimento econômico, promovem o turismo e aumentam investimentos no local (Stankova \& Vassenska, 2015; Getz, 2008).

Para Chiang et al. (2016) os festivais são atividades únicas por fomentarem a identidade, revitalizarem atrações estagnadas, são um veículo de conservar e celebrar a cultura, fomentar as redes sociais e acelerar economias. Vivenciar a cultura está ligado às motivações em realizar e participar deste tipo de evento (Akhoondnejad, 2016).

A literatura identifica benefícios econômicos, sociais e culturais na realização de eventos especiais e festivais (Akhoondnejad, 2016; Grappi \& Montanari, 2011; Gursoy; Kim \& Uysal, 2004). Para os residentes, dentre os nos benefícios proporcionados encontram-se: melhorar a qualidade de vida, promover entretenimento e relacionamentos pessoais, gerar oportunidade de emprego e infraestrutura, revitalizar tradições e aumentar o apego ao lugar. O estudo realizado por Stankova e Vassenska (2015), enfatizou a importância dos eventos e festivais serem analisados pelos estudos no turismo de acordo com sua contribuição na conservação do patrimônio cultural e das tradições, não somente pela perspectiva econômica.

A criação de uma imagem favorável nos eventos e festivais é apontado por Deng, Li e Shen (2013) como sendo relevante no desenvolvimento a longo prazo do destino, pois ajudam na imagem favorável do destino 


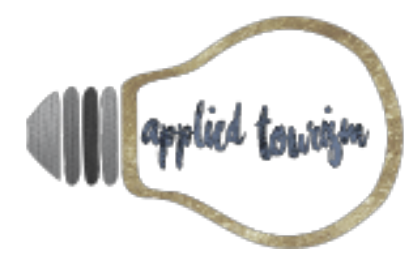

Volume 4, número 1, 2019, p. 41- 56

potencializando sua atratividade para demandas turísticas. Portanto, a percepção dos visitantes é um caminho valioso para investigar a percepção destes perante diversos aspectos que formam a imagem na mente destes consumidores.

Do Valle, Mendes e Guerreiro (2012) apontam a importância dos estudos relacionando residentes, eventos e imagem de destino. Destacam duas questões importantes a se considerar: o papel dos moradores no processo de construção da imagem de um destino pelos turistas, principalmente por sua influência boca-a-boca; e a contribuição dos eventos como atrativo turístico que embora diminua a sazonalidade de destinos turísticos, só é sustentável se os residentes também são considerados público alvo pelos gestores.

Os autores argumentam que o envolvimento e a participação dos locais são fundamentais para garantir o sucesso do evento. A comunicação de marketing do evento deve ter como alvo a harmonia com a percepção dos residentes em relação a imagem projetada do evento e não somente focar no turista. Ao pesquisarem o evento Allgarve em Algarve, Portugal, identificaram que a forma como foi implementado o evento a princípio não foi bem recebida pelos residentes, o que poderia influenciar negativamente na propagação aos turistas, no entanto os governos perceberam a importância dos residentes como importantes atores no processo e mudaram suas estratégias comunicacionais.

\section{Imagem de eventos e festivais}

A maioria das pesquisas sobre imagem no campo do turismo se concentram na imagem dos destinos devido a importância que estudos nessa vertente possuem no gerenciamento do destino, no desenvolvimento sustentável e na competitividade (Pereira, 2013). Pode-se mencionar relevantes estudos na literatura sobre a imagem de destino como os de Baloglu e McCleary (1999); Echtner e Ritchie (1993); Chen e Tsai (2007); Beerli e Martin (2004).

Apesar da reconhecida importância de estudos sobre imagem de destino ou marca de destino, Deng et al. (2013) assinalam que a imagem de eventos ainda é pouco investigada analisada pela ciência, portanto, as dimensões da imagem de evento ainda têm muito para serem exploradas nas pesquisas.

No estudo sobre imagem de lugar, Stylidis, Biran, Sit e Szivas (2014) apontam que as investigações trabalham com variáveis de análise que possuem uma dinâmica passível de mudança constante. Os fatores relacionados a imagem mudam com o tempo, como a percepção de benefícios ou custos econômicos e sociais, desenvolvimento ao destino, melhoria ou degradação da qualidade de vida (Prayag, Hosany \& Nunkoo, 2013; Small, 2007; Gursoy et al. 2004; Delamere, 2001) como as expectativas, experiencias anteriores. Portanto, estudos 


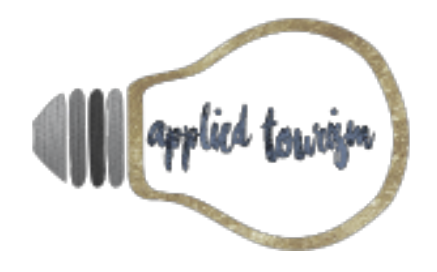

Volume 4, número 1, 2019, p. 41- 56

nessa área indicam que não existe um modelo teórico único para avaliar a imagem de destino, as investigações escolhem os atributos de imagem de acordo com a realidade de cada destinação (Pereira, 2013).

Lai (2018) afirma que muitos estudiosos consideram a imagem de evento um constructo multidimensional semelhante a imagem de destino, que pode abranger vários componentes. Santos, Zucco e Krause (2015) sublinham que cada evento ou festival terá uma imagem distinta derivada de um conjunto único de componentes.

Paralelamente a isso, os autores Stilydis et al. (2014) afirmam que percepção de uma imagem de lugar positiva propicia a percepção dos impactos de forma mais positiva. Neste mesmo panorama, a imagem do evento perante os moradores será mais positiva se estes perceberem os benefícios se sobrepondo aos custos relacionados aos impactos gerados da atividade.

Deng et al. (2013) desenvolveram uma escala para mensurar a imagem de evento. Inicialmente utilizaram o referencial de imagem de marca de Keller como base teórica que resultou em cinco dimensões rotuladas como: benefícios, facilidade, serviço, tema e conteúdo do evento. Acrescenta-se que o estudo identificou que a dimensão benefício percebido foi o aspecto mais importante da imagem do evento. O benefício está ligado a experiencia no evento e entendido como ganhos percebidos

No contexto brasileiro, Santos, Zucco e Kraus (2015) adaptaram a escala de Deng et al. (2013) para averiguar a se imagem de um festival de cerveja. O resultado da pesquisa revelou que a imagem do evento é vista como positiva e foi apontado a necessidade de melhorar algumas questões relacionadas a qualidade de serviços que estão presentes na dimensão infraestrutura. Como apontado nas conclusões do estudo de Deng et al. (2013), os custos e benefícios percebidos fazem parte da percepção da imagem. Em face ao levantamento dos impactos percebidos, estudiosos podem estabelecer modelos de planejamento que visem minimizar impactos negativos (Vargas-Sánchez, Porras-Bueno \& Plaza-Mejía, 2011).

Farias (2015) ao analisar um festival popular no nordeste brasileiro utilizou como base teórica os estudos de Deng et al. (2013) e Crompton e Mckay (1997) para compreender a imagem percebida pelos visitantes perante os benefícios, as instalações, os serviços, o conteúdo do evento e tema. Os benefícios foram melhores avaliados pelos inquiridos enquanto que as instalações foram vistas mais negativamente. A satisfação do visitante diante do (perante o) festival está relacionada ao conteúdo do evento, tema e instalações.

Os benefícios econômicos são salientados como a principal razão para o desenvolvimento de eventos, mas podem trazem possíveis consequências como causar o desequilíbrio entre o desenvolvimento econômico e Berselli, C. \& Zucco F. D. (2019). A IMAGEM DA FESTA NACIONAL DO DOCE - FENADOCE EM PELOTAS (RS), BRASIL, PERANTE A PERCEPÇÃO DOS RESIDENTES. Applied Tourism, 4(1), 41- 56. 


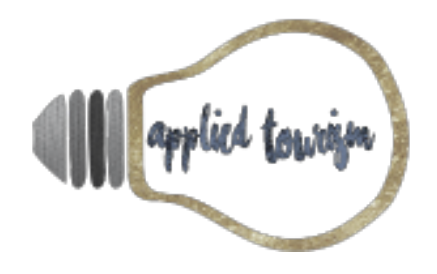

Volume 4, número 1, 2019, p. 41- 56

social na comunidade (Delamere, 2001; Gursoy et al. 2004). Nos festivais, se a geração de receitas for o principal motivo para sua promoção, a autenticidade diminui por passar a ter caráter mais comercial, e consequentemente os moradores passam a perceber a atividade como teatralizada (Gursoy et al. 2004). Ou seja, neste tipo de evento se a geração de receitas for o principal motivo para sua promoção, a autenticidade diminui por passar a ter caráter mais comercial para atrair um maior número possível de turistas (Small, 2007; Gursoy et al., 2004). Consequentemente os moradores passam a perceber a atividade como teatralizada e gerando impactos negativos na comunidade (Gursoy et al., 2004).

Delamere (2001) definiu impactos sociais positivos e negativos percebidos em festivais comunitários. Os benefícios divididos entre: para a comunidade e individuais. Foram compreendidas variáveis relacionadas a imagem, identidade e bem-estar da comunidade, experimentar coisas novas e desenvolver novas habilidades e talentos. Os custos sociais compreenderam variáveis relacionadas a superlotação, transito, lixo, ruído, intrusão e interrupção na vida dos moradores.

Em estudo posterior, Gursoy et al. (2004) identificaram os impactos sociais e econômicos percebidos em festivais nas comunidades entendidos como coesão comunitária, benefícios econômicos, incentivos sociais e custos sociais. Os resultados do estudo revelaram que a coesão comunitária e incentivos sociais para a comunidade foram as percepções mais relevantes perante festivais e eventos especiais em detrimento da contribuição econômica que poderia ocasionar a comunidade.

Small (2007) buscou compreender a percepção dos residentes sobre os impactos sociais resultantes de festivais comunitários. Neste estudo foram identificados fatores de impactos positivos e negativos experimentados a nível pessoal, nomeados como: inconveniência, frustação pessoal, oportunidades de entretenimento e socialização. E impactos positivos e negativos percebidos a nível da comunidade nomeados identidade e coesão da comunidade, crescimento e desenvolvimento da comunidade e consequências comportamentais (Small, 2007).

O autor identificou aspectos positivos percebidos devido à realização do evento, como o senso de identidade e união da comunidade relacionado a demonstração de singularidade que o festival proporciona, oportunidades de entretenimento, socialização, crescimento e desenvolvimento da comunidade. Os fatores negativos estão relacionados ao incômodo provocado aos moradores e suas rotinas devido à realização do evento, sentimentos de frustação e consequências comportamentais negativas advindas da realização do festival (Small, 2007).

Prayag , Hosany e Nunkoo (2013) desenvolveram um estudo sobre a percepção dos impactos, atitude e apoio dos residentes para um mega-evento. Foram investigados os impactos econômicos, socioculturais e ambientais 


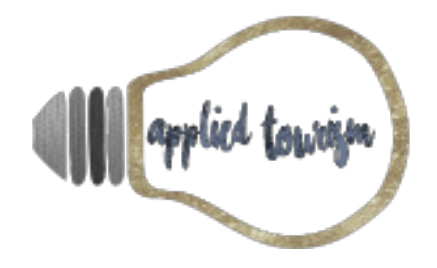

Volume 4, número 1, 2019, p. 41- 56

percebidos positivos e negativos antes da realização do evento. Os impactos econômicos e socioculturais percebidos, tanto positivos como negativos, influenciaram na atitude geral ao contrário dos impactos ambientais positivos e negativos. A atitude geral foi entendida como um importante mediador da percepção dos impactos positivos e negativos.

No contexto brasileiro, Fiuza (2016), incluiu os quatro níveis de impactos: econômicos, sociais, ambientais e culturais. Seu estudo foi aplicado para identificar a perceção dos residentes quantos aos impactos de um festival cultural. Foi identificado cinco fatores intitulados desenvolvimento local, mudança de comportamento, identidade e coesão da comunidade, socialização e inconveniencias.

Os principais impactos negativos encontrados foram o aumento no tráfego e dificuldades em encontrar vaga de estacionamento durante o evento. O principal impacto positivo foi a promoção do município como destino turístico consolidado, as demais percepções mais relevantes foram sobre melhora da imagem da cidade para os turistas, o estímulo de melhorias na infraestrutura urbana, a superlotação das instalações públicas, a preservação da cultura local, reforço da identidade da comunidade e o aumento do consumo de produtos em empresas da cidade. Além disso, os moradores não percebem o festival causando desconforto cultural, danos ao meio ambiente e poluição visual.

\section{METODOLOGIA}

Este estudo se caracteriza como sendo exploratório e descritivo. Quanto aos procedimentos foi realizado pesquisa bibliográfica e levantamento de campo. Em relação ao método, a pesquisa é quantitativa. (Prodanov \& Freitas, 2013). O estudo foi realizado com questionários que receberam análise numérica e estatística dos resultados alcançados (Gerhardt \& Silveira, 2009; Fonseca, 2002).

Feitas estas explanações, para o questionário foram elaboradas questões a partir dos estudos de Deng et al. (2013), Prayag et al. (2013), Small (2007), Gursoy et al. (2004) e Delamere (2001).

Para a avaliação da imagem, foram elaboradas com 21 variáveis e opções de respostas a partir da escala likert de 7 pontos de concordância. Uma segunda parte da pesquisa é constituída por dados demográficos, pessoais e sociais dos respondentes totalizando 8 questões.

Os questionários foram aplicados em abril de 2018 no Mercado Público e entorno com os residentes de Pelotas, obtendo 125 questionários, dos quais obteve-se 111 válidos. 


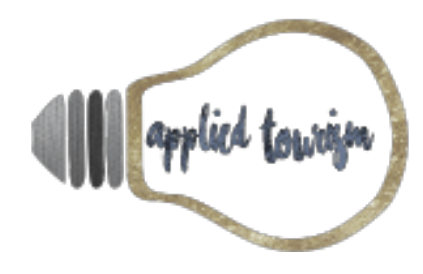

Volume 4, número 1, 2019, p. 41- 56

Para medir a consistência interna das variáveis do formulário usou-se o coeficiente Alfa de Cronbach, que quantifica a confiabilidade do constructo de 0 a 1 , sendo considerado um índice satisfatório 0,70 segundo Cronbach (1951). Em trabalhos de natureza exploratória Hair at al. (2009) indica que o valor pode diminuir para 0,60. Neste estudo, o Alfa de Cronbach alcançado foi de 0,890, valor considerado aceitável. Os resultados permitiram demonstrar evidências satisfatórias quanto a confiabilidade e consistência interna do questionário, apresentando valores dentro do exigido pela literatura.

\section{ANÁLISE DOS DADOS E DISCUSSÃO DOS RESULTADO}

De acordo com os dados demográficos dos respondentes foi possível identificar o perfil dos residentes entrevistados em Pelotas, abrangendo gênero, idade, escolaridade, ocupação profissional, média salarial familiar, tempo de residência em Pelotas, número de edições da Fenadoce frequentados, e se vai só ou acompanhado na edição deste ano.

Os dados demográficos são apresentados na Tabela 1. Quanto ao gênero dos respondentes foram predominantemente femininos (59,5\%) sobre os masculinos (40,5\%), estando de acordo com a característica do município de ser predominantemente composto por mulheres conforme aponta o IBGE (2018) ${ }^{\mathrm{I}}$.

Em relação a faixa etária, a ampla maioria da amostra corresponde a idade de 18 a 30 anos (51,4\%), seguidos de 31 a 40 anos $(20,7 \%)$ e 41 a 50 anos (15,3\%). Os menores números foram encontrados para de 51 a 60 anos (9,0\%) e acima de 60 anos (3,6\%). Pode-se afirmar que o resultado compreender em maior número jovens adultos está de acordo com os dados do IBGE (2018) para o município.

Sobre o nível de escolaridade, a maior parte dos respondentes possuem grau de Escolaridade Superior Incompleto (39,6\%), Superior Completo (24,3\%) e Pós-graduação (19,8\%). No que tange a ocupação profissional, apontou uma maior parte dos respondentes disseram serem estagiários ou estudantes (36,9\%), empregados assalariados (16,2\%) e funcionários públicos (14,4\%).

A maior parte da amostra diz receber recebe até 2 salários mínimos (34,2\%), de 2 a 4 salários mínimos (22,5\%) e respondentes que preferiram não responder à questão (18\%). O menor número de respostas foi para acima de 20 salários mínimos, representando 2,7\% da amostra. Sabendo-se que 1 salário mínimo corresponde a R \$954,00, pode-se perceber pelos resultados alcançados que a maior frequência da amostra é constituída de residentes

\footnotetext{
${ }^{\text {I }}$ https://cidades.ibge.gov.br/brasil/rs/pelotas/panorama

${ }^{\text {II }} \mathrm{http}: / /$ www.normaslegais.com.br/legislacao/decreto9255_2017.htm

Berselli, C. \& Zucco F. D. (2019). A IMAGEM DA FESTA NACIONAL DO DOCCE - FENADOCE EM PELOTAS (RS), BRASIL, PERANTE A PERCEPÇÃO DOS RESIDENTES. Applied Tourism, 4(1), 41- 56.
} 


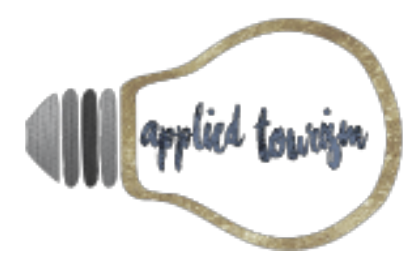

Volume 4, número 1, 2019, p. 41- 56

pertencentes a classe $C^{\text {III }}$ da população brasileira conforme os parâmetros do critério de classificação econômica Brasil da ABEP (2016) e a menor frequência pertence à classe $\mathrm{A}^{\mathrm{IV}}$.

Tabela 1: Perfil dos respondentes do pré-teste $(\mathrm{n}=111)$.

\begin{tabular}{|c|c|c|}
\hline Gênero & Frequência & Porcentagem \\
\hline Feminino & 66 & $59,5 \%$ \\
\hline Masculino & 45 & $40,5 \%$ \\
\hline Total & 111 & $100 \%$ \\
\hline Faixa etária & Frequência & Porcentagem \\
\hline 18 a 30 anos & 57 & $51,4 \%$ \\
\hline 31 à 40 anos & 23 & $20,7 \%$ \\
\hline 41 à 50 anos & 17 & $15,3 \%$ \\
\hline 51 à 60 anos & 10 & $9,0 \%$ \\
\hline Mais de 60 anos & 4 & $3,6 \%$ \\
\hline Total & 111 & $100,0 \%$ \\
\hline Escolaridade & Frequência & Porcentagem \\
\hline Superior incompleto & 44 & $39,6 \%$ \\
\hline Superior Completo & 27 & $24,3 \%$ \\
\hline Pós-graduado(a) & 22 & $19,8 \%$ \\
\hline Médio Completo & 11 & $9,9 \%$ \\
\hline Fundamental completo & 7 & $6,3 \%$ \\
\hline Total & 111 & $100,0 \%$ \\
\hline Ocupação Profissional & Frequência & Porcentagem \\
\hline Estagiário/estudante & 41 & $36,9 \%$ \\
\hline Empregado assalariado & 18 & $16,2 \%$ \\
\hline Funcionário público & 16 & $14,4 \%$ \\
\hline Conta própria/autônomo & 14 & $12,6 \%$ \\
\hline Empresário & 11 & $9,9 \%$ \\
\hline Não trabalho/desempregado & 7 & $6,3 \%$ \\
\hline Aposentado & 2 & $1,8 \%$ \\
\hline Dona de casa & 2 & $1,8 \%$ \\
\hline Total & 111 & $100,0 \%$ \\
\hline Renda familiar (em salários mínimos) & Frequência & Porcentagem \\
\hline Até 2 salários mínimos & 38 & $34,2 \%$ \\
\hline De 2 a 4 salários mínimos & 25 & $22,5 \%$ \\
\hline Prefiro não responder & 20 & $18,0 \%$ \\
\hline De 10 a 20 salários mínimos & 13 & $11,7 \%$ \\
\hline De 4 a 10 salários mínimos & 12 & $10,8 \%$ \\
\hline Acima de 20 salários mínimos & 3 & $2,7 \%$ \\
\hline Total & 111 & $100,0 \%$ \\
\hline
\end{tabular}

Fonte: Pesquisa direta (2018)

\footnotetext{
III Para a Associação Brasileira de Empresas de Pesquisas (2016) a renda das classes C1 e C2 está média entre R\$ $1.625,00$ e $\mathrm{R} \$ 2.700,00$ respectivamente

IV Para a Associação Brasileira de Empresas de Pesquisas (2016) a renda média da classe A é de R\$ 20.888,00. Berselli, C. \& Zucco F. D. (2019). A IMAGEM DA FESTA NACIONAL DO DOCE - FENADOCE EM PELOTAS (RS), BRASIL, PERANTE A PERCEPÇÃO DOS RESIDENTES. Applied Tourism, 4(1), 41- 56.
} 


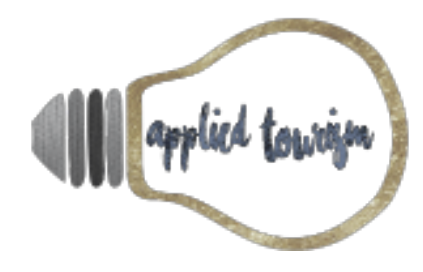

Volume 4, número 1, 2019, p. 41- 56

A Tabela 2 apresenta os resultados quanto ao tempo de residência dos entrevistados em Pelotas, os dados apresentados se mostraram bastante pulverizados, demonstrando que a amostra varia bastante quanto o tempo de residência no município. Um maior número de respondentes disse morar em Pelotas a mais de 40 anos $(15,32 \%)$ e de 35 a 39 anos (13,51\%). Já de 10 a 14 anos, 15 a 19 anos e 20 a 24 anos, todos atingiram mesmo percentual de respostas (12,61\%). Poucos foram os inquiridos que moram de 5 a 9 anos em Pelotas (5,41\%) e os moradores com menos de 5 anos (8,11\%).

Tabela 2: Tempo de residência em Pelotas dos entrevistados ( $n=111)$.

\begin{tabular}{lcc}
\hline Tempo de Residência & Frequência & Porcentagem \\
\hline Mais de 40 anos & 17 & $15,3 \%$ \\
De 35 a 39 anos & 15 & $13,5 \%$ \\
De 10 a 14 anos & 14 & $12,6 \%$ \\
De 15 a 19 anos & 14 & $12,6 \%$ \\
De 20 a 24 anos & 14 & $12,6 \%$ \\
De 30 a 34 anos & 11 & $9,9 \%$ \\
De 25 a 29 anos & 10 & $9,0 \%$ \\
Menos de 5 anos & 9 & $8,1 \%$ \\
De 5 a 9 anos & 6 & $5,4 \%$ \\
Não respondeu & 1 & $0,9 \%$ \\
\hline
\end{tabular}

Fonte: Pesquisa direta (2018).

Buscou-se saber a frequência de edições da Fenadoce que os residentes haviam prestigiado até a presente pesquisa, conforme apresentado na Tabela 3. Do total dos 111 respondentes houve uma porcentagem de igual número de edições frequentadas da Fenadoce para as respostas de 4 a 6 edições assim como de 7 a 9 edições, ambas totalizaram 20,72\% dos respondentes, seguidos de 18,92\% responderam ter frequentado entre 10 a 12 edições. A menor frequência encontrada foi de $0,9 \%$ para a frequência de 22 a 24 edições. Estes resultados estão congruentes com a faixa etária dos respondentes e está de acordo com os dados da feira, uma vez que em 2018 ocorrerá a $26^{\circ}$ edição do evento que fará 32 anos de existência.

Tabela 3: Número de edições da Fenadoce frequentadas pelos respondentes $(\mathrm{n}=111)$.

\begin{tabular}{lcc}
\hline Edições frequentadas & Frequência & Porcentagem \\
\hline De 4 a 6 edições & 23 & $20,7 \%$ \\
De 7 a 9 edições & 23 & $20,7 \%$ \\
De 10 a 12 edições & 21 & $18,9 \%$ \\
De 1 a 3 edições & 18 & $16,2 \%$ \\
De 13 a 15 edições & 12 & $10,8 \%$ \\
De 16 a 18 edições & 7 & $6,3 \%$ \\
De 19 a 21 edições & 3 & $2,7 \%$ \\
Mais de 25 edições & 3 & $2,7 \%$ \\
De 22 a 24 edições & 1 & $0,9 \%$ \\
\hline
\end{tabular}

Fonte: Pesquisa direta (2018).

Foi realizada uma última pergunta em relação ao perfil dos frequentadores da Fenadoce, relacionado a descobrir como pretendem ir acompanhados ou não ao evento. Os dados apresentados na tabela 4 apresentam o total de 


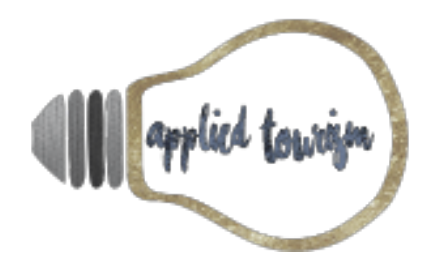

Volume 4, número 1, 2019, p. 41- 56

respostas considerando múltiplas respostas. Nesta questão obteve-se 130 respostas, por este motivo ultrapassou $100 \%$ da amostra.

Tabela 4: Respostas quanto ao perfil de companhia dos frequentadores da próxima Fenadoce ( $\mathrm{n}=111)$.

\begin{tabular}{lcc}
\hline Você vai só ou acompanhado a Fenadoce este ano? & Frequência & Porcentagem \\
\hline Acompanhado da família & 69 & $62,2 \%$ \\
Acompanhado companheiro(a)/marido/esposa/namorado(a) & 29 & $26,15 \%$ \\
Acompanhado pequeno grupo amigos & 23 & $20,7 \%$ \\
Acompanhado de um grande grupo de amigos & 6 & $5,4 \%$ \\
Sozinho & 3 & $2,7 \%$ \\
\hline Total & 130 & $117,1 \%$ \\
\hline
\end{tabular}

Fonte: Pesquisa direta (2018).

Pode-se perceber a possibilidade dos frequentadores irem mais de uma vez ao evento e podem variar de companhia. A grande maioria da amostra, totalizando 69 respostas, pretende ir acompanhado da família $(62,2 \%)$ e acompanhados do companheiro(a)/ marido/ esposa/ namorado(a) (26,15\%). Percebe-se que o evento possui um público com perfil familiar.

Apresentados os resultados demográficos e perguntas pessoais parte-se para apresentação dos resultados das médias alcançadas quanto a percepção dos residentes à imagem da Fenadoce.

Salienta-se que dentre as maiores médias alcançadas pela Imagem, os resultados encontram-se dentro dos cinco pontos. Verifica-se através das médias encontradas que os respondentes percebem V18 - A Fenadoce como uma oportunidade de entretenimento (4,59), V14 - Oferece oportunidades de recreação familiares $(5,18)$, V15 - A prestação de serviços públicos e de infraestrutura melhora com a Fenadoce (5,15), V17 - A reputação nacional de Pelotas através de exposição na mídia melhora com a Fenadoce $(5,14)$ e a V19 - Fenadoce permite boas experiencias culturais $(5,06)$.

Estes resultados indicam que o residente percebe positivamente a realização da Fenadoce, principalmente os benefícios sociais denominados oportunidades de entretenimento, oportunidade de recreação familiares e experiencias culturais entendidos como oportunidades de socialização. Small (2007) entende essas variáveis como oportunidade de entretenimento e interação social durante os festivais. Estes resultados são similares em parte aos achados de Gursoy et al. (2004) onde a coesão comunitária e os incentivos pessoais foram as principais contribuições percebidas ao se realizar festivais.

Os principais benefícios econômicos percebidos pelos residentes com a realização do festival são a prestação de serviços públicos e de infraestrutura melhoradas e a reputação nacional de Pelotas através de exposição na mídia melhorada com a Fenadoce.

Berselli, C. \& Zucco F. D. (2019). A IMAGEM DA FESTA NACIONAL DO DOCE - FENADOCE EM PELOTAS (RS), BRASIL, PERANTE A PERCEPÇÃO DOS RESIDENTES. Applied Tourism, 4(1), 41- 56. 


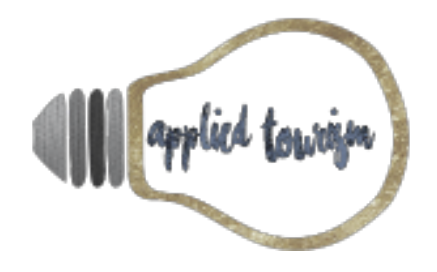

Volume 4, número 1, 2019, p. 41- 56

As menores médias apresentadas são aquelas abaixo de três pontos. A menor média recebida foi para a afirmação V34 - O estacionamento disponível aos visitantes da Fenadoce serem apropriados $(2,14)$, ou seja, existe um alto grau de discordância quanto a este quesito. Esta infraestrutura do evento está ligada a percepção da imagem do evento e necessita de cuidado pelos gestores para melhorar o fornecimento desta infraestrutura.

Outras duas variáveis que receberam maiores pontuações de discordância são quanto a percepção perante V22 A qualidade de vida dos moradores serem prejudicadas durante a realização da Fenadoce $(2,45)$ e V21 - A rotina dos residentes são alteradas de forma negativa durante a Fenadoce $(2,68)$. Interpreta-se que os residentes não percebem estes aspectos de forma negativa, sendo entendido como um resultado muito positivo. Estes indicativos vão ao encontro do postulado por Prayag et al. (2013), a realização de eventos oferece duas oportunidades principais à comunidade, fortalecer o vínculo da comunidade e a participação nos eventos contribuem com o bem-estar e a qualidade de vida da comunidade.

\section{CONSIDERAÇÕES FINAIS}

Os resultados desta pesquisa além de um consistente aprofundamento teórico não só avançam a teoria na área, também podem ter utilidade prática no planejamento e gestão de futuros festivais. Os organizadores do evento e os demais setores interessados, os stakeholders, precisam conhecer a imagem de evento para um gerenciamento mais otimizado, minimizando percepções negativas e destacando aspectos positivos. Assim, pesquisas nesta perspectiva são importantes para compreender e entender como é a percepção de um festival por sua comunidade anfitriã.

Este estudo contribui para o corpo de pesquisa sobre eventos e festivais no turismo, tendo em vista que há uma maior expressividade de estudos relacionados a imagem de destinos turísticos (Lai, 2018; Deng, Li, \& Shen, 2013). As variáveis relacionadas a imagem de evento e festivais baseados nos estudos dos autores contidos no referencial teórico e destacados na metodologia mostraram-se bastante consistentes; com os resultados foi possível verificar a aplicabilidade de mensuração de proposta por este estudo.

Os resultados apontaram que a percepção dos residentes de maneira geral é positiva perante a imagem da Fenadoce. Os aspectos relacionados a imagem receberam pontuações positivas para os elementos relacionados a benefícios a comunidade, custos percebidos, qualidade de serviços e infraestrutura, podendo ser considerado somente o estacionamento como fator crítico que merece atenção dos gestores. Estes resultados corroboram com estudos que identificam como principais benefícios ao se realizarem eventos e festivais estão relacionados 


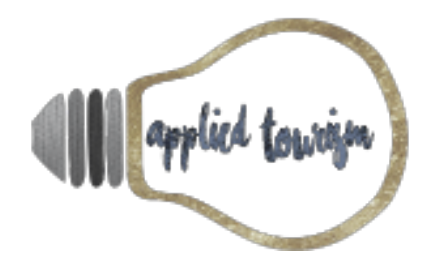

Volume 4, número 1, 2019, p. 41- 56

a oportunidade de entretenimento e socialização, desenvolvimento da comunidade através de benefícios econômicos e sociais (Prayag et al. 2013; Small, 2007; Gursoy et al. 2004; Delamere, 2001).

Nesta pesquisa o maior público de respondentes alcançado foi o feminino, estando de acordo com o (IBGE, 2017), a maior parte dos respondentes estão na faixa dos 18 a 30 anos, com ensino superior incompleto, renda de até 2 salários mínimos, e boa parte dos respondentes foram estudantes. A respeito do tempo de residência, os dados se mostraram pulverizados assim como o número de edições do festival frequentadas. É importante destacar que a maioria das respostas demonstrou que o evento tem um público com perfil para famílias ou casais.

Gerencialmente, estes resultados fornecem parâmetros para os gestores do festival demandarem esforços em corrigir os aspectos negativos e neutros para uma imagem mais positiva do evento. Além disso, conhecer o perfil dos residentes que frequentam o evento e a suas percepções podem resultar em um aumento na frequência anual no evento, uma vez que a Fenadoce irá para a 26 edição em 2018 e é realizado em um período de 15 dias.

Mesmo os resultados desta pesquisa terem se mostrado positivos de maneira geral para as respostas dadas quanto a relação à infraestrutura e serviços oferecidos, sugere-se aos gestores criarem novas estratégias de entretenimento e infraestrutura para melhor receber e atrair uma maior demanda do perfil de visitantes identificados na pesquisa - famílias ou casais - uma vez que a maior percepção foi quanto a oportunidade de entretenimento que a Fenadoce oferece.

Quanto ao principal aspecto percebido negativamente, a infraestrutura oferecida "estacionamento" necessita de maior atenção dos gestores. Como apontam os resultados, os respondentes possuem média salarial de até 2 salários mínimos, indicando que para que os visitantes minimizem uma percepção negativa dos custos relacionados ao valor de ingresso e estacionamento, os serviços e infraestrutura oferecidos necessitam serem de excelência. Ademais, o custo benefício percebido é fator decisivo para percepções mais positivas tanto para moradores como turistas. Por fim, sublinha-se com este estudo a necessidade e a importância de pesquisas de investigação da imagem percebida perante os gestores de eventos.

Como limitação de pesquisa, salienta-se que os resultados diante das percepções dos residentes foram referentes ao período anterior a realização do evento, o que pode divergir da percepção dos mesmos durante ou após o evento, conforme apontado por Chiang et al. (2016). Além disso a escolha de somente um local para a realização do questionário pode ter limitado uma abrangência maior de opiniões do universo dos moradores de Pelotas.

Sugere-se que pesquisas futuras sejam realizadas durante e após o festival para possibilitar o cruzamento das informações no sentido de obter um panorama completo da percepção dos moradores quanto ao seu festival. Berselli, C. \& Zucco F. D. (2019). A IMAGEM DA FESTA NACIONAL DO DOCE - FENADOCE EM PELOTAS (RS), BRASIL, PERANTE A PERCEPÇÃO DOS RESIDENTES. Applied Tourism, 4(1), 41- 56. 


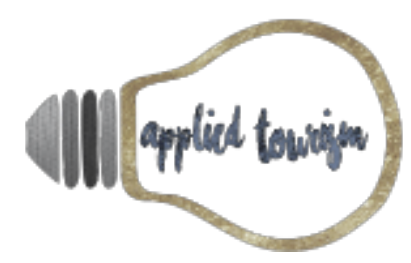

Volume 4, número 1, 2019, p. 41- 56

Também se salienta a necessidade de utilização de um maior número de respondentes que permitam outras analises estatísticas. 


\section{REFERÊNCIAS}

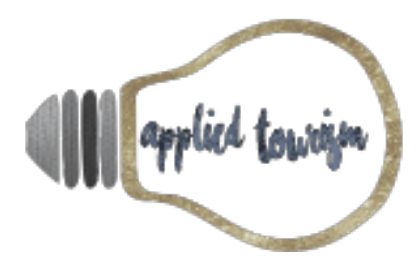

Volume 4, número 1, 2019, p. 41- 56

Akhoondnejad, A. (2016). Tourist loyalty to a local cultural event: The case of Turkmen handicrafts festival. Tourism Management, 52, pp. 468-477.

Baloglu, S., \& McCleary, K. W. (1999). A model of destination image formation. Annals of tourism research, 26(4), 868-897.

Beerli, A., \& Martin, J. D. (2004). Factors influencing destination image. Annals of tourism research, 3, pp. 657-681.

Chen, C.-F., \& Tsai, D. (2007). How destination image and evaluative factors affect behavioral intentions? Tourism management, 4, pp. 1115-1122.

Chiang, L., Xu, A., Kim, J., Tang, L., \& Manthiou, A. (2016). Investigating festivals and events as social gatherings: the application of social. Journal of Travel \& Tourism Marketing, 34(6), pp. 779-792.

Crompton, J. L., \& McKay, S. L. (1997). Motives of visitors attending festival events. Annals of tourism research, 24(2), 425439.

Delamere, T. A. (2001). TOWARD THE SOCIAL IMPACTS OF COMMUNITY FESTIVALS, PART II: VERIFICATION OF THE SCALE. Event Management, 7, pp. 25-38.

Deng, C. Q., Li, M., \& Shen, H. (2013). Developing a measurement scale for event image. Journal of Hospitality \& Tourism Research, 39(2), pp. 245-270.

Do Valle, P. O., Mendes, J., \& Guerreiro, M. (2012). Residents' participation in events, events image, and destination image: a correspondence analysis. Journal of Travel \& Tourism Marketing, 29(7), 647-664.

Echtner, C. M., \& Ritchie, J. B. (1993). The measurement of destination image: An empirical assessment. Journal of travel research, 31(4), 3-13.

Farias, F. d. (2015). Ampliar os horizontes e conhecer coisas novas: a imagem de eventos a partir da perspectiva dos visitantes da Festa de São João de Campina Grande, Paraíba. Dissertação (mestrado em Turismo e Hotelaria) pela Universidade Vale do Itajaí.

Fiuza, T. F. (2016). A percepção dos residentes sobre os impactos gerados por festivais: O caso da Oktoberfest de Santa Cruz do Sul (RS). Dissertação (mestrado em Turismo e Hotelaria) pela Universidade vale do Itajaí.

Fonseca, J. J. S. (2002). Metodologia da pesquisa científica. Fortaleza: UEC. Apostila

Gerhardt, T. E. \& Silveira, D. T. (2009). Método de Pesquisa. Porto Alegre: Editora da UFRGS.

Getz , D., \& Page, S. J. (2016). Progress and prospects for event tourism research. Tourism Management, 52, pp. 593-631.

Getz, D. (2008). Event tourism: Definition, evolution, and research. Tourism Management, 29(3), pp. 403-428.

Getz, D., Andersson, T., \& Carlsen, J. (2010). Festival management studies: Developing a framework and priorities for comparative and cross-cultural research. International Journal of Event and Festival Management, 1(1), 29-59.

Guerreiro, M., Oon do Valle, P., \& Mendes, J. (2011). Allgarve events: Implications for the Algarve image. Tourism, 59(2), pp. 183-202. 


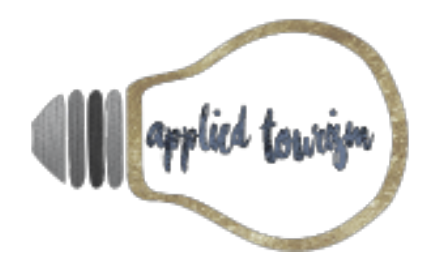

Volume 4, número 1, 2019, p. 41- 56

Gursoy, D., Kim, K., \& Uysal, M. (2004). Perceived impacts of festivals and special events by organizers: an extension and validation. Tourism Management, 25(2), pp. 171-181.

Grappi, S. \& Montanari, F. (2011). The role of social identification and hedonism in affecting tourist re-patronizing behaviours: The case of an Italian festival. Tourism Management, v. 32, n. 5, p.1128-1140.

IBGE. (2017). Insituto Brasileiro de Geografia e Estatistica. Acesso em 01 de 10 de 2017, disponível em https://cidades.ibge.gov.br/brasil/rs/pelotas/panorama

Kotler, P. \& Gertner, D. (2002). Country as brand, produt and beyond: a place marketing and brand management perspective. Brand Management, 9-261.

Lai, K. (2018). Influence of event image on destination image: The case of the 2008 Beijing Olympic Games. Journal of Destination Marketing \& Management, 7, 153-163.

Laing, J., \& Frost, W. (2013). Food, wine... heritage, identity? Two case studies of Italian diaspora festivals in regional Victoria. Tourism Analysis, 18(3), 323-334.

Machado, D. F. C., de Lima Medeiros, M., \& Luce, F. B. (2011). A miopia do marketing de destinos turísticos. Tourism \& Management Studies, (1), 654-663.

Pereira, M. d. (2013). Avaliação da imagem do destino turístico: fatores pessoais e estímulos na perspectiva do turista de Porto Belo (SC), Brasil. . Dissertação (Mestrado em Turismo e Hotelaria) Universidade Vale do Itajaí, 145p.

Pimentel, E., Pinho, T., \& Vieira, A. (2006). Imagem da marca de um destino turístico. Turismo, Visão e Ação, 8(2), 283-299.

Prayag , G., Hosany, S., \& Nunkoo, R. (2013). London residents' support for the 2012 Olympic Games: The mediating effect of overall attitude. Tourism Management, 36, 629-640.

Prodanov, C. C., \& de Freitas, E. C. (2013). Metodologia do trabalho científico: métodos e técnicas da pesquisa e do trabalho acadêmico-2a Edição. Editora Feevale.

Santos , T., Zucco, F. D., \& Kraus, C. B. (2015). Imagem de eventos turísticos: Perspectivas do Festival Brasileiro da Cerveja, Blumenau-SC. Turismo-Visão e Ação, 1, 128-149.

Small, K. (2007). SOCIAL DIMENSIONS OF COMMUNITY FESTIVALS: AN APPLICATION OF FACTOR ANALYSIS IN THE DEVELOPMENT OF THE SOCIAL IMPACT PERCEPTION (SIP) SCALE. Event Management, 11, pp. 45-55.

Stankova, M., \& Vassenska , I. (2015). Raising cultural awareness of local traditions through festival tourism. (U. d. Algarve, Ed.) Tourism \& Management Studies, 11(1).

Stylidis, D., Biran, A., Sit, J., \& Szivas, E. M. (2014). Residents' support for tourism development: The role of residents place image and perceived tourism impacts. Tourism Management (45) 260-274.

Vargas-Sánchez, A., Porras-Bueno, N., \& Plaza-Mejía, M. d. (2011). Explaining residents' attitudes to tourism: Is a universal model possible? Annals of tourism research, 38, pp. 460-480.

Wheeler, F., Frost, W., \& Weiler, B. (2011). Destination brand identity, values, and community: A case study from rural Victoria, Australia." 28.1. Journal of Travel \& Tourism Marketing, 28(1), pp. 13-26. 